BULLETIN Bulletin hispanique

HISPANIQUE Université Michel de Montaigne Bordeaux

114-2 | 2012

Varia

\title{
Pedro de Espinosa, Poesía, edición de Pedro Ruiz
}

Pérez

Castalia-Edhasa, Madrid, 2011

Clara Marías Martínez

(2) OpenEdition

Journals

Edición electrónica

URL: https://journals.openedition.org/bulletinhispanique/2298

DOI: 10.4000/bulletinhispanique.2298

ISSN: $1775-3821$

Editor

Presses universitaires de Bordeaux

Edición impresa

Fecha de publicación: 31 diciembre 2012

Paginación: 970-977

ISBN: 978-2-86781-855-4

ISSN: 0007-4640

\section{Referencia electrónica}

Clara Marías Martínez, «Pedro de Espinosa, Poesía, edición de Pedro Ruiz Pérez», Bulletin hispanique

[En línea], 114-2 | 2012, Publicado el 23 julio 2013, consultado el 02 agosto 2022. URL: http://

journals.openedition.org/bulletinhispanique/2298 ; DOI: https://doi.org/10.4000/bulletinhispanique. 2298

Este documento fue generado automáticamente el 2 agosto 2022

All rights reserved 


\title{
Pedro de Espinosa, Poesía, edición de Pedro Ruiz Pérez
}

\author{
Castalia-Edhasa, Madrid, 2011
}

Clara Marías Martínez

\section{REFERENCIA}

Pedro de Espinosa, Poesía, edición de Pedro Ruiz Pérez - Madrid, Castalia-Edhasa, 2011, 448 p. (colección: Clásicos Castalia, 312) - ISBN: 978-84-9740-412-9

1 Treinta y seis años después de la edición llevada a cabo por Francisco López Estrada para Espasa-Calpe, Pedro Ruiz Pérez, catedrático de Literatura Española de la Universidad de Córdoba, vuelve a poner a disposición de los lectores la poesía de Pedro Espinosa (1578-1650), dentro de la colección de Clásicos Castalia, desde 2010 con nueva apariencia -portadas unificadas en color rojo vino y con imágenes- tras la incorporación de la editorial a Edhasa. Culmina así el proceso de revitalización del poeta antequerano a través de nuevas ediciones de sus obras, impulsado en los últimos años por Belén Molina Huete (Flores de poetas ilustres y Fábula del Genil, 2005), Inoria Pepe Sarno y José María Reyes Cano (Flores de poetas ilustres, 2006) y Tania Domínguez García (Espejo de Cristal, 2008), continuadores del esfuerzo editor de López Estrada (Poesías completas, 1975 y Obra en prosa, 1991), a su vez heredero del pionero trabajo de Francisco Rodríguez Marín (Obras, 1909). Con esta reciente edición de su poesía, Pedro Ruiz Pérez se suma a la difusión de la obra de Pedro Espinosa, complementando así su contribución crítica, que había enriquecido en los últimos tiempos el conocimiento de este autor -en general más atendido por su labor de antólogo que por su propia escritura- con artículos sobre su lírica profana $(2003,2005)$, su lírica sacra $(2007,2010)$, y cuestiones de transmisión y canon $(2006,2010)$. Este nuevo volumen de «Poesía. Siglo XVII» de la colección Clásicos Castalia puede dividirse en tres partes. La primera, que precede a la edición, incluye una introducción, una noticia bibliográfica de las obras de Pedro Espinosa, una bibliografía secundaria, y una nota previa que aclara los criterios de 
edición. La segunda parte la constituye la edición de las poesías, divididas en apartados según los testimonios, y acompañadas de notas a pie de página referentes a cuestiones que afectan a cada poema en su conjunto. Esta segunda parte se complementa con el apartado "Otros textos», que recoge la convocatoria y explicación de una justa a Ignacio de Loyola en la que participó Espinosa, las notas al «Psalmo de penitencia» que parecen del propio poeta, y dos poemas que Pedro Ruiz Pérez excluye del corpus pero incopora al volumen para facilitar su consulta. La tercera parte está formada por cuatro apéndices, el primero de los cuales, más extenso, contiene las variantes alternativas en cada poesía al testimonio tomado como texto base de la edición, y un cuerpo de anotaciones que atañen a los versos. Los otros apéndices son útiles índices: de composiciones, de primeros versos, y de expresiones y términos anotados. La obra se cierra con una breve noticia sobre el editor. La introducción de Pedro Ruiz Pérez, que consta de casi medio centenar de páginas, escritas cinco años antes de ver finalmente la luz, se divide en tres apartados: «Un hombre de su tiempo» (pp. 7-22), aproximación biográfica basada en la información suministrada por Rodríguez Marín y López Estrada y contexto histórico y literario; «Los textos de Espinosa: escritura y transmisión» (pp. 22-45) valoración ordenada y completa de los distintos testimonios de su poesía; y «Claves poéticas» (pp.45-54), exposición sintética de la dimensión de la poesía de Espinosa y de su lugar dentro del canon. En cuanto a la biografía de Espinosa, Ruiz Pérez destaca su «intenso dinamismo y variedad, con claro reflejo en su escritura» (p. 7), y la estructura en cuatro etapas: «Los años de formación» (1578-1605), «La etapa religiosa» (1606-1615), «El poeta en la corte señorial» (1615-1624), y «De la publicación al silencio» (1624-1650). De los primeros años, señala la sólida formación humanista recibida por Espinosa en Antequera, la incorporación al círculo de poetas de esta ciudad (Martín de la Plaza, Bautista de Mesa, Fernández de Alarcón...), y los contactos con eruditos y escritores de Granada, Córdoba, y Sevilla, red plasmada en su antología de 1605. Al describir la fase religiosa, primero como eremita en la serranía de Antequera, y luego como capellán y sacerdote en Archidona, Ruiz Pérez subraya los lazos de Espinosa con lo mundano, ya que participa en justas y certámenes de temática sacra que le suponen un mayor reconocimiento, como muestra su inclusión en la antología manuscrita de Juan Antonio Calderón. De la fase en que Espinosa conecta con la casa ducal de Medina Sidonia, coincidente con el triunfo del gongorismo en la corte, Ruiz Pérez muestra su ambivalencia entre el estatus de poeta-criado que elogia a su señor y el de poeta retirado que explora la vena moral y envía sus obras a quien comulga con esta sensibilidad, el erudito Rodrigo Caro. En la fase final perviven ambas caras del poeta antequerano: hasta 1636 sigue vinculado al duque de Medina Sidonia, y se suceden sus impresos, de carácter moral, didáctico, y cortesano, analizados con detalle por Ruiz Pérez; después, la soledad y el silencio. La utilidad de este recorrido se refuerza al enmarcar el investigador la trayectoria biográfica de Espinosa en los avatares históricos y políticos, y al recalcar en cada fase el panorama literario y artístico en que inscribe su obra. De este modo, el lector advierte con mayor claridad la renovación y el cambio de época, de estilo y de valores que fueron guiando el quehacer poético de Espinosa. El editor no se centra en detalles anecdóticos de la vida del poeta (por ejemplo, no menciona, como sí hacía López Estrada siguiendo a Rodríguez Marín, a Cristobalina Fernández de Alarcón como amor frustrado del poeta y motor de su desengaño), sino que presta mayor atención a la evolución literaria. En línea con este enfoque, el siguiente apartado de la introducción, sobre la escritura y transmisión de los textos de Espinosa, es el más extenso. En él, Pedro Ruiz Pérez presta especial 
atención al vehículo de transmisión de la poesía y por ello revisa las variadas circunstancias, difusión y características de cada testimonio impreso -el cauce más frecuente- y manuscrito, siguiendo su orden cronológico. Comienza el recorrido con las Flores de poetas ilustres de España, impreso en 1605, «primer aldabonazo del 'arte nuevo'» (p.24) en el que el antólogo incluyó diecinueve composiciones propias, lo que lo convierte en el tercer testimonio más nutrido de la poesía de Espinosa. El editor incide en la dispositio de la antología, y en la lectura a la que conduce, "apoyada en concomitancias internas entre los poemas [...] donde el engarce de motivos se corresponde con marcadas alternancias métricas» (p. 25). Las poesías del antequerano coinciden con el conjunto en la variedad métrica, temática, tonal, estilística, y destacan por su experimentación formal (con la «canción informe» o «boscarecha», origen de la silva), por el gusto por los pasajes metapoéticos, y por la ruptura de modelos anteriores. Ruiz Pérez señala que tanto en la «Fábula de Genil»-quizá el poema más renombrado de Espinosa- como en su lírica sacra, se otorga mayor peso al preciosismo de las descripciones y al conceptismo, alejándose así del intimismo y del ideal de naturalidad propios de la corriente petrarquista. El segundo testimonio, también impreso, es la «Relación de las fiestas a la beatificación de Ignacio de Loyola» (1610), cuyo relator, Luque Fajardo, incluyó cuatro poemas de Espinosa. Para el editor, estos poemas de transición oscilan entre lo retórico y ornamental, y la búsqueda de ingenio y el conceptismo, presentando una mayor dificultad. Así, el antequerano parece aprender al mismo tiempo de Quevedo y de Góngora, pues sus juegos de palabras permiten, según Ruiz Pérez, «consolidar así otro de los campos de contacto y fusión que tan irreal hacen la división metodológica en culteranismo y conceptismo» (p. 28). El tercer testimonio, manuscrito, es la antología recopilada por Juan Antonio Calderón y dedicada al V Marqués de Carpio en 1611, que contiene el corpus más amplio de poemas de Espinosa bajo el nombre de «Pedro de Jesús»-, la mayoría religiosos -tres de ellos ya incluidos en la edición de las justas. Para el editor, estamos ante el primer conjunto de poesías reunido de forma unitaria y con un criterio que parece autorial. Por ello Ruiz Pérez se detiene en analizar la disposición de los poemas en series con núcleos temáticos, enfoque muy fructífero que tal vez resultaría más claro acompañado de un esquema visual de dicha agrupación. Para el investigador, esta preocupación de Espinosa por su poesía demuestra que, lejos de ser un eremita alejado del mundo, se trataba de un autor consciente de que que la renovación lírica consistía también en la «redefinición del papel del escritor y su relación con su propia obra» (p. 32). Del mismo modo destaca la variedad de acercamientos del antequerano a la temática religiosa, desde el circunstancial -por el traslado de la imagen de Monteagudo-, hasta el contemplativo de los salmos; y la alternancia de moldes, desde los más breves (sonetos, y algún epigrama), predominantes, hasta los extensas (silvas, romances, estancias aliradas). El cuarto testimonio, de 1615, constituye el primer impreso autónomo de Espinosa, un pliego con la relación en tercetos de las exequias del séptimo duque de Medina Sidonia. Ruiz Pérez considera que este extenso poema sirve en parte de transición entre la poesía academicista de la etapa anterior y la poesía cortesana de la siguiente, si bien en él, además de la intención panegírica y noticiera, aparecen también reflexiones morales y religiosas, de mayor protagonismo en testimonios posteriores. La quinta fuente de la poesía de Espinosa sería un posible códice manuscrito de autor, que Pedro Ruiz Pérez trató de recomponer en la investigación recogida en Studia Aurea (2006, accesible online) y aquí resumida. Las huellas de este probable códice autorial son los manuscritos derivados de los que Espinosa debió de enviar a Rodrigo Caro, conservados en el British 
Museum (BM, Add. 20793), con quince poemas, de los que cinco no aparecen en testimonios anteriores; y en el códice perdido de la Biblioteca del Palacio Arzobispal de Sevilla (PA, 33-180-6), del que se conserva una copia en la Biblioteca Central del CSIC (CSIC, RM-5177). A partir de los datos suministrados por Rodríguez Marín en su edición de 1909, y de la copia realizada por el hijo de Quirós de los Ríos y ahora en el CSIC, Ruiz Pérez reconstruye el contenido del códice sevillano perdido, con veintiseis textos de Espinosa (algunos, varias versiones de un mismo poema), muchos ya presentes, con variantes, en testimonios anteriores. Para el editor, el manuscrito BM constituiría una antología articulada en dos partes, una con predominio de la vertiente sálmica, y otra con predominio de formas neoclásicas. El manuscrito PA, por abrirse igualmente con la «Soledad del Gran Duque», por contener distintas versiones del «Salmo de Penitencia» y de la epístola a Antonio Moreno, y por las semejanzas y divergencias con BM, demuestra para Ruiz Pérez la existencia de un manuscrito autorial del que proceden ambos, ya que descarta la filiación directa entre ellos o que procedan de fuentes independientes. Esta convincente propuesta del editor refuerza su idea de Pedro Espinosa como poeta preocupado por la difusión, ordenación, y reelaboración de sus versos, y por la "construcción en 'texto' de sus 'textos' originalmente dispersos» (p. 42). Los últimos testimonios de la poesía del antequerano los recoge Ruiz Pérez bajo el epígrafe «1625. Clausura impresa», dado que en dicho año se edita en pliego suelto el «Psalmo de penitencia», copiado en códices previos, de forma experimental (silva) y retórica patética; y el «Elogio al retrato de don Manuel Alonso de Guzmán», obra panegírica en prosa que incluye poemas intercalados y al final, entre ellos la moral «Soledad del Gran Duque». Sin duda, este apartado es la aportación más valiosa de la introducción, ya que aborda aspectos que no aparecían en la edición de López Estrada, como la evolución estilística de Espinosa, la ordenación de los testimonios de su poesía, y dentro de cada uno la disposición y sentido de sus versos. Además, resume la propuesta del códice autorial perdido a través de la comparación de los poemas incluidos en los manuscritos conservados BM y PA (este último en la copia del CSIC). Este estudio de los testimonios impresos y manuscritos, autónomos y colectivos, es el esqueleto que articula la edición de Ruiz Pérez. El tercer apartado de la introducción, «Claves poéticas», más breve, se detiene en los motivos del «relativo fracaso» de la antología de 1605, según Ruiz Pérez relacionados con su innovadora disposición, alejada de la «concepción orgánica de la obra petrarquista» y de la «barroca fórmula de las 'varias rimas'» (pp. 46-7). El editor trata de buscar el porqué de esta innovación, que atribuye a la concepción «académica» (pública, lúdica, humorística) de la poesía que Espinosa pudo aprehender del entorno antequerano; y a la mengua de la implicación sentimental y el intimismo a favor de lo expresivo y experimental. El análisis del estilo se centra en la «Fábula del Genil» y en la poesía panegírica, que el investigador relaciona con otros poemas anteriores y contemporáneos. Ruiz Pérez valora el gongorismo de Espinosa, su horacianismo (que considera más bien neoestoicismo), y su compromiso con la renovación, a través de la «difuminación de los límites de los géneros consagrados» y del "predominio del componente narrativo o descriptivo» (p. 53), que resulta en una poesía más intelectual y objetiva. El apartado se cierra con el rechazo a la aplicación de marbetes como «manierismo» y «cultismo» a la poesía del antequerano, pues Pedro Ruiz Pérez prefiere considerarla dentro del "proceso de asentamiento de la poética barroca» (p.54). Tras la introducción, la «Noticia bibliográfica» ordena los testimonios -incluyendo los que sólo contienen prosa- en «Impresos propios», «Poemas en impresos ajenos», «Manuscritos», "Testimonios 
dudosos o perdidos» y «Ediciones modernas». Se suelen consignar cuántas composiciones de Espinosa contiene cada testimonio, se incluye la descripción de los manuscritos, y de algunos de los impresos (Flores, Entierro, Psalmo de penitencia), se detallan además las ediciones modernas o los ejemplares conocidos de las ediciones antiguas -para más información remite a la entrada realizada para el Diccionario filológico de Castalia. El editor también indica en cada testimonio o edición con poesía la forma abreviada de referirse a él en el aparato crítico, si bien resultaría más claro y facilitaría la consulta que esta información apareciera exenta, por ejemplo en la página anterior a la edición o en la anterior al Apéndice 1. En cuanto a la «Bibliografía», con más de cincuenta entradas, facilita al lector los principales artículos y monografías dedicados a la obra de Espinosa y a su antología; de las recogidas, las más numerosas son las contribuciones de Lara Garrido, López Estrada, Molina Huete, y el propio editor. De gran utilidad también es la recopilación de «Instrumenta y textos frecuentes en la anotación», a los que cabría añadir las ediciones empleadas de los poetas cuyos versos aparecen más a menudo en las notas en relación con la obra de Espinosa, principalmente Luis de Góngora, San Juan de la Cruz y Garcilaso de la Vega. Finalmente, en la nota previa, Ruiz Pérez explica que, en coherencia con el peso otorgado en la introducción a la sucesión de los testimonios y a la disposición de los poemas dentro de los mismos, ha decidido organizar los poemas de Espinosa según estos criterios. Es decir, mientras que López Estrada, en su edición, hacía una división temática en «poesía del amor profano», «poesía mitológica», «poesía festiva y burlesca», "poesía religiosa», "poesía espiritual», "poesía panegírica», "poesía laudatoria en preliminares», y «poesías dudosas», Ruiz Pérez defiende que «seguir los avatares de estos versos parece [...] más productivo que tratar de someterlos a una imposible clasificación temática o métrico-formal» (p. 23), por lo que los ordena en función de cómo aparecen en cada testimonio o de la reconstrucción que hace de la voluntad editorial del autor. No cabe duda de que esta decisión ofrece una nueva lectura y un nuevo acercamiento crítico, pues facilita el estudio de la evolución poética del antequerano, de su actitud editorial; y de la relación entre las formas y temas escogidos, y la entidad y destinatarios del testimonio. En cuanto al criterio ecdótico, debido a la transmisión poco compleja de la mayoría de las poesías, Ruiz Pérez decide escoger como texto base el testimonio correspondiente a cada poema -aunque hay excepciones- y anotar las variantes de testimonios sucesivos. Por otra parte, tiene en cuenta las enmiendas y lecturas de editores anteriores para aceptarlas o rechazarlas, controla las enmiendas oee ingenii, y omite codices descripti y testimonios secundarios. Respecto a la ortografía, puntuación y acentuación, Ruiz Pérez explica que opta por un criterio modernizador, pero tiene en cuenta las reglas internas de prosodia y rima, y enumera los casos en los que ha mantenido los usos gráficos de los testimonios. Esta elección facilita la lectura. La edición propiamente dicha no es una antología, sino que comprende la poesía de Pedro Espinosa conocida hasta la fecha, un corpus de ochenta y siete poemas. Respecto a la edición precedente de López Estrada, añade dos poemas (el soneto «Oh, amor divino...» y las octavas «Rimbombe el parche...», pp. 209-303) que proceden de un testimonio impreso en 1637, las «Flores poéticas y justa al triunfo de los desagravios del Santísimo Sacramento», que Molina Huete recuperó en 2009. De los seis poemas de autoría dudosa para López Estrada, todos procedentes del Elogio al retrato, Ruiz Pérez descarta definitivamente dos sonetos, que recoge en "Otros textos», y prefiere incluir otros cuatro en el corpus de Espinosa, con atinados argumentos estilísticos y extra-textuales. En cuanto a los sonetos preliminares, que López Estrada unía en un mismo apartado, 
Ruiz Pérez los sitúa cronológicamente: el dedicado a la obra de Rodrigo Caro en 1622, entre el códice autorial de c. 1623 y el «Salmo de penitencia» de 1625; y los que elogian obras de 1626-1642, al final, antes de la justa de 1637. Como ya anunciaba la nota previa, la dispositio trata de reconstruir la sucesión de los testimonios y de acercarse a la organización dictada por la conciencia autorial, por ello cada poema aparece en el apartado del testimonio que lo recoge por vez primera, y no se repite aunque haya otros testimonios que lo contengan, sino que se indican las variantes que aporten estos en las notas finales. Por ejemplo, el soneto sobre San Ignacio "Como tarja o blasón...», aparece en el apartado de la «Relación» de la fiesta a la beatificación del mismo, de 1610, y no en el apartado del testimonio manuscrito de las Flores de 1611, cuyas variantes se encuentran en las notas finales. Para no perder la información sobre qué poemas se repiten en testimonios posteriores y qué lugar ocupan en los mismos, quizá sería útil recoger el título en el lugar correspondiente, aunque no se reproduzca el texto completo, así como añadir al final un índice de los poemas incluidos en cada manuscrito e impreso siguiendo el orden en que aparecen (como los realizados en la introducción de los códices BM y PA). Dado que de algunos poemas hay varias copias, recoger en texto completo aquellas que por su gran número de variantes pudieran considerarse reescrituras, como sucede con el «Salmo de penitencia», facilitaría el estudio comparado de las distintas versiones, más difícil de hacer a partir del aparato crítico. Dentro de cada testimonio, Ruiz Pérez intenta reproducir el orden más cercano a la voluntad del autor; así, el soneto laudatorio de Espinosa al recopilador de las Flores de 1611 se recoge al final de este apartado, por considerarse que debió de ser escrito con posterioridad a los demás. Para evitar confusiones, es necesario precisar que el criterio de dispositio (que cada texto aparezca en su serie en el testimonio más temprano), y el criterio de fijación textual (ofrecer el texto más fiable en la edición) no siempre coinciden en un mismo testimonio. Por ejemplo, la «Soledad del gran Duque de Medina Sidonia» aparece en el apartado de "Códices manuscritos [...] c. 1623», para dejar constancia de su primera inclusión en los códices manuscritos BM y PA, que por sus errores remiten, para Ruiz Pérez, a una primera redacción presente en el códice autorial propuesto. Sin embargo, puesto que del mismo poema hay una versión definitiva, impresa en 1625, es esta la que sirve de base para la fijación textual, empleándose los manuscritos para enmendar erratas. Otro ejemplo son las décimas a San Ignacio, que se incluyen en el apartado de la «Relación» impresa en 1610, pero que en su fijación textual incluyen una estrofa final que no estaba en dicho testimonio y que se toma de manuscritos posteriores. En casos como el primero, Ruiz Pérez señala en nota a pie de página el testimonio empleado para la fijación textual, en otras ocasiones es necesario acudir al aparato crítico final para ver a través de las variantes cuál ha sido el testimonio primario y cuáles los secundarios (por ejemplo, en el poema 2, presente en el apartado de Flores el singular "guirnalda» se toma del manuscrito antequerano, como se indica en la nota final correspondiente a ese verso). El criterio seguido para la fijación textual, pues, resulta sólido y convincente -valga como ejemplo el que prescinda de títulos consagrados como «Epístola a Heliodoro» o «Soledad segunda» porque no tienen respaldo en los testimonios. En algunos casos requeriría quizá una aclaración más explícita en las notas finales o en la nota previa a la edición; o para que fuera más evidente visualmente, podría recogerse bajo el título del poema el testimonio del que se toma el texto -y el ejemplar en el caso de las ediciones con varios-, siempre y cuando éste no coincida con el apartado en que se encuentra el poema. La edición se complementa con dos aparatos de notas: uno, a pie de página, más breve, lo que facilita 
la lectura de los poemas; otro, más extenso, al final (pp.321-423), que recoge las variantes y las explicaciones más exhaustivas. La labor de Ruiz Pérez es encomiable, dado que, frente al laconismo de otros editores, la gran mayoría de los poemas están anotados, lo que facilitará la lectura y el estudio de Pedro de Espinosa tanto a hispanohablantes como a hispanistas extranjeros. En las notas a pie de página suele haber breves introducciones explicativas a los poemas, indicaciones sobre su disposición en el testimonio o sobre su transmisión, cuestiones de atribución y fuentes, aclaraciones métricas y expresivas, relaciones con otros textos contemporáneos... es decir, cuestiones que afectan al poema en su conjunto o a gran parte de él, como indica el que el número de nota vaya volado en el título o número de la poesía. Como ejemplos de algunas de las propuestas más sugerentes, valgan la indicación de que el soneto «Rompe la niebla»...considerado habitualmente antigongorino, podría ser una burla de las imitaciones ariostescas (p. 80); el hecho de que las estrofas "A una mujer gorda» acentúen su carácter burlesco si se tiene en cuenta su disposición en las Flores (p. 84); la interpretación como epigrama del poema «Pobre viste...», que en la edición de López Estrada se titula «madrigal» (p. 95); la presencia de «Campespe»-editado por López Estrada como «campestre»-, en textos de otros autores con el significado que adquiere en el soneto «Pues son vuestros pinceles...» (p. 100); la explicación de los poemas «A San Acacio» (p.136), «A nuestra Señora de Monteagudo» (p. 160), "Al gran Duque» (p. 279) „AA la color azul suya» (p. 285) u «iOh, amor divino...!» (p. 299-300); la indicación de la semejanza del soneto en alejandrinos «Como el triste piloto» con uno de Du Bellay (p. 141); su crítica a la atribución a Luis Martín de la Plaza de un poema (p. 163); o su apoyo a la atribución a Espinosa de la relación del entierro del Duque de Medina Sidonia y el contraste entre este poema y la reflexión sobre las exequias del tratado Espejo de cristal (p.171-2). En cuanto a las anotaciones finales, se encuentran junto a las variantes y escasas enmiendas -que están bien justificadas y mejoran la comprensión de ciertos versos oscuros en la edición de 1975-, y remiten a versos concretos de cada composición. Resulta explicable que por su extensión no se situaran a pie de página, si bien, al menos en el caso de las que definen un término complejo, esta disposición facilitaría la comprensión inmediata de los poemas por parte de los lectores menos avezados. Las notas finales constituyen otra de las mayores aportaciones de esta edición, ya que cubren numerosos aspectos: cuestiones de puntuación, de métrica, de significado, lecturas de otros editores, correspondencias verbales con otros autores... En un poeta como Espinosa, resultan imprescindibles las explicaciones de personajes de obras literarias («Doralice», «Palinuro»), mitos («Arión», «Flegra»), topónimos reales y míticos («Getulia»), montes («Hibla»), ríos («Hidaspes,» «Pactolo»), pueblos («agatirsos»), cultismos, alusiones astronómicas («epiciclos»); y términos propios del mundo de la pintura («trasfloro», «perfil»), el bordado (alcatifa, giraspe), la música («canto de garganta»), o las plantas y flores («elicrisios», «gualda»)... Se agradece especialmente que las notas no se limiten a una definición -casi siempre de Covarrubias-, sino que aclaren el sentido del término en el contexto del poema (por ejemplo, «acicates» en el poema 6, o «discante» en el poema 18), en el contexto social, religioso o histórico (por ejemplo, los arcabuces vueltos del poema 50, o el debate de la salvación por la fe o las obras en el poema 60), o según los conocimientos científicos y médicos del momento. Hay pasajes especialmente complejos (como la última octava del poema 59, o el verso 94 del poema 77) a los que se dedica una exposición detallada. De igual modo, se aclaran juegos de palabras, dilogías, disemias, juegos conceptistas (Caro/ caro), neologismos («toribios»), hipérbatos, imágenes («pía de Juno»), y cultismos 
(«ecuóreo»). Muy útiles son también las notas referentes a los frecuentes proverbios y refranes (para los que Ruiz Pérez recurre a Covarrubias y Correas); y a las sentencias e ideas morales, casi siempre de raíz estoica, que jalonan especialmente los poemas del núcleo manuscrito. Igual de enriquecedoras son las que recogen las relaciones verbales o estructurales y las similitudes entre los poemas de Espinosa y los de Góngora (muy frecuentes), San Juan de la Cruz, y Garcilaso de la Vega; o los textos de la biografía de Rivadeneira sobre Ignacio de Loyola que sirven de punto de partida a los poemas sobre el santo. Para futuros estudios, resulta muy fructífera la anotación de paralelismos entre los versos de Espinosa y pasajes de sus obras en prosa, y la recurrencia de fragmentos de unos poemas en otros (por ejemplo), los pasajes de la llamada «Boscarecha» que reaparecen en la «Carta a Antonio Moreno». Esta tendencia, junto a los poemas reescritos en sucesivas fuentes, la predilección por términos como «lindes», y las frecuentes reflexiones metapoéticas, que Ruiz Pérez suele recalcar, es una de las facetas más interesantes de la poesía de Espinosa. La aportación que suponen estas casi setecientas notas a expresiones y términos se acentúa si se tiene en cuenta que menos de ochenta de las mismas aparecían en la edición de 1975. En definitiva, el apéndice de notas resulta imprescindible para cualquier acercamiento a las muchas vetas de la poesía de Espinosa, todas ellas de gran interés, desde el elogio desmesurado de cómo el duque de Medina Sidonia juega a la pelota hasta el soneto al infierno, desde los salmos confesionales hasta la alternancia entre ética y lujo preciosista de la «Soledad del gran Duque de Medina Sidonia». Confiamos, pues, en que esta edición, tan cuidada (apenas diez erratas) como accesible, además de facilitar la incorporación de la poesía de Pedro Espinosa -junto a otros autores habitualmente expulsados del canon aúreo- a los planes de estudio universitarios, contribuya también a impulsar nuevos análisis por parte de los hispanistas, pues, en palabras de Pedro Ruiz Pérez, «se impone la necesidad de un acercamiento más detallado a sus textos, a partir de la recuperación de su historicidad y la renuncia a la imposición de una imagen unitaria basada en una presunta biografía» (p.53). De este modo, los versos del poeta antequerano podrán continuar en los próximos años, con su «subido modo poético» (p. 108), levantándose de la marginación impuesta por «su escasa sintonía con la sensibilidad contemporánea y el encajonamiento historiográfico entre los grandes poetas del período» (p. 53).

\section{AUTORES}

\section{CLARA MARÍAS MARTÍNEZ}

Universidad Complutense, Madrid 